Portland State University

PDXScholar

Engineering and Technology Management

Faculty Publications and Presentations

$12-1-2017$

\title{
Technology Readiness Levels Improving R\&D Management: A Grounded Theory Analysis
}

Joao Ricardo Lavoie

Portland State University

Tugrul Unsal Daim

Portland State University, tugrul@etm.pdx.edu

Follow this and additional works at: https://pdxscholar.library.pdx.edu/etm_fac

Part of the Engineering Commons

Let us know how access to this document benefits you.

\section{Citation Details}

J. R. Lavoie and T. U. Daim, "Technology Readiness Levels Improving R\&D Management: A Grounded Theory Analysis," 2017 Portland International Conference on Management of Engineering and Technology (PICMET), Portland, OR, 2017, pp. 1-9.

This Article is brought to you for free and open access. It has been accepted for inclusion in Engineering and Technology Management Faculty Publications and Presentations by an authorized administrator of PDXScholar. Please contact us if we can make this document more accessible: pdxscholar@pdx.edu. 


\title{
Technology Readiness Levels Improving R\&D Management: A Grounded Theory Analysis
}

\author{
Joao Ricardo Lavoie, Tugrul U. Daim \\ Engineering and Technology Management Department, Portland State University, Portland, USA
}

\begin{abstract}
The strategic management of an organization is well understood and there are several different frameworks and methodologies available to develop and implement strategies that will put the organization on the right track and make it more competitive. Nevertheless, the ability to manage technology and to assess and choose the right technologies to be used and to be invested in is not that well understood and developed. The technology readiness is important to be measured and managed, so that organizations have the chance to make better decisions on which technologies to rely on and when. Technology Readiness Levels (TRL) is a method developed by NASA nearly 40 years ago and it has been proven to help organizations to manage their technologies. The aim of this paper is to understand, in more details, how TRL can help organizations and what are the potential implications of using it to the betterment of R\&D management. Interviews were conducted with technology managers and researchers. Grounded theory was used to analyze the data, and the results indicate that TRLs can improve R\&D management. Some hypotheses were formulated and should be confirmed or refuted by future research.
\end{abstract}

\section{INTRODUCTION}

The importance of developing and implementing a strategy for an organization to succeed is well understood and dates back from the 60 's.

Identifying, analyzing and understanding factors and players that influence the organization, both from the internal and external environments, is mandatory for the strategic management, and there are several methods that help in conducting these analyzes. There are, however, some factors within the internal and external environments that should be analyzed and managed with equal care and competence. One of these factors is technology - the strategic management of technology is vital for an organization to know its capabilities on product/service development, plan on how to attack markets in the medium and long-term and manage its portfolio (technology and product) in a proper fashion.

One of the biggest challenges in managing technology is to properly choose which technologies to invest in and to know when technologies are ready or mature enough to be considered for a particular system/product. The poor selection and management of technologies can cause serious financial losses and, in the long term (if the poor management persists), can result in the organization being unable to compete in markets where it used to thrive.

As opposed to the strategic management of organizations in general, there are not many methods developed for assessing and evaluating technology maturity/readiness. The Technology Readiness Levels (TRL) were created by NASA [1] and later improved [2], as a way to measure how ready a certain technology is in order to decide if that technology should or should not be used in space missions and systems. Later on, other government agencies such as DoD (Department of Defense) and DoE (Department of Energy) started to use the method, and more recently some private companies are looking to adapt and implement the method to their technology management processes. To put it in simple words, the main reason why it is an issue to determine technology readiness is because if the organization fails to do so, it will certainly lose time and money. Choosing the wrong technologies to invest in and inserting not-ready-enough technologies into new products or systems will definitely result in budget and schedule overruns, plus additional work to be done and possibly a considerable amount of damage to the organization's image and reputation. According to [3], quality issues and failing to identify a technology`s readiness accurately are among the main reasons that cause cost overruns. Moreover, according to [4], a well-performed technology assessment is key to avoid problems with cost, schedule and performance goals.

The TRL is a scale from 1 to 9 that measures to what extent a technology is ready to be applied. In its original form, the scale was created with the aerospace industry in mind (figure 1), but now there are other versions of the scale, tailored for a variety of different industries/sectors.

In this paper, we investigate the benefits TRL brings to organizations and try to establish connections between these benefits and the betterment of research and development (R\&D) functions. Also, we identify some of the issues associated with TRLs; metrics that would substitute and/or complement the tool; and the most common and important R\&D issues organizations face.

The rest of the paper sections are divided as follows: an explanation of the research method, a literature review, the results and discussion and conclusions. Lastly, we propose some future research opportunities.

\section{RESEARCH METHOD}

The present study has the objective of investigating the existence of a correlation between the implementation and use of technology readiness levels and the betterment of R\&D management, ultimately resulting in competitive advantage to organizations. 
In order to accomplish the objective, the methodologies used are interviews with practitioners and researchers in the technology management field and a grounded theory analysis of the gathered data [5]. Grounded theory is a qualitative data analysis method, developed by Glaser and Straus (1967) [6], in which data collection and data analysis occur simultaneously and theory is created grounded in the data. It is an inductive process, by which hypotheses are generated based on observations from the data, instead of generating hypotheses based on literature and testing them by ways of collecting and analyzing data. According to [7], "Grounded Theory provides rigorous yet flexible guidelines that begin with openly exploring and analyzing inductive data and leads to developing a theory grounded in data".

The participants were interviewed using an online survey tool. The sample is comprised of 36 respondents, representing industry, academia and research labs, both from the private and public sectors. The questions (in its vast majority open-ended ones) were aimed at identifying how respondents perceive the importance of TRL for the R\&D function, the specific benefits TRL bring to organizations and the most common R\&D challenges organizations face nowadays, hoping to shed a light on how (and if) TRL could be used to mitigate those challenges.

A literature review is conducted to lay the theoretical foundations of TRL - its history, basic characteristics, issues, potential, etc. and also to serve as a starting point to speculate on how TRLs might bring benefits to technology/engineering managers and their organizations. The interviews are applied to get a sense of how TRLs are currently implemented and used in organizations, as well as to understand the benefits and/or expected benefits TRLs yield to technology managers.

\section{LITERATURE REVIEW}

Technology maturity is the degree to which a certain technology is capable of producing the results that are expected. For most of the researchers, the terms 'technology maturity' and 'technology readiness' are synonyms and therefore are used interchangeably. However, for some scholars, there are differences between the two terms. According to [8], technology maturity would be related to the technology itself, while technology readiness would be related to the application or context where that technology will be used. As the author says, "A mature product may possess a greater or lesser degree of readiness for use in a particular system context than one of lower maturity". Regardless of the possible differences in the meaning of these terms, it is widely acknowledged that organizations should be keen in determining the maturity and/or readiness of their technologies, for the organizations who are not aware of its importance and fail to do so might end up by investing in the wrong technologies for the wrong applications, wasting time and capital. According to [9], determining and managing the readiness of technologies - most importantly for high-tech companies - is of the essence in order to thrive. Clausing and Holmes also mention the importance of having a technology readiness assessment in place. As the authors state, "technology readiness is not only a critical component of strategic management; it is essential to business performance" [10].

There are not plenty of metrics and tools developed to measure how ready a technology is. The most popular method is the Technology Readiness Level (TRL), a scale developed by NASA to help them assess the technologies they were considering to include into systems for space missions. The TRL is a nine-point scale that ranges from the very basic ideas (level 1) up to mission-proven technologies (level 9) - fig. 1. The scale has been gaining popularity and is being acknowledged as the main method to measure a technology readiness, a standard way to inform organizations over their developing technologies [11]-[16]. Moreover, TRLs are proven to be beneficial in managing a technology portfolio and choosing technologies to invest in [17]-[21].

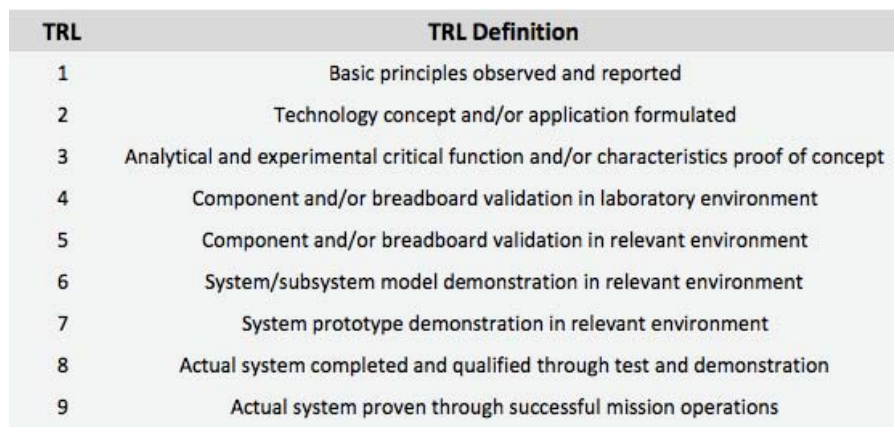

Fig. 1. TRL definitions by NASA, adapted from [22]

In order to use the method, one should analyze the characteristics of the technology being assessed and compare it with the definitions contained in the scale - thus finding the technology readiness level of that particular technology. The result would be a snapshot in time of the degree of development concerning that specific technology, and decisions could be made based on this information.

TRL's were born at NASA around 40 years ago, when scientists from the space agency realized they needed a way to assess and compare technological developments prior to deciding which technologies to insert in space mission systems. The first version of the scale had only seven levels [1], see fig. 2. Later on, the first version was improved, when the eight and ninth levels were included [22].

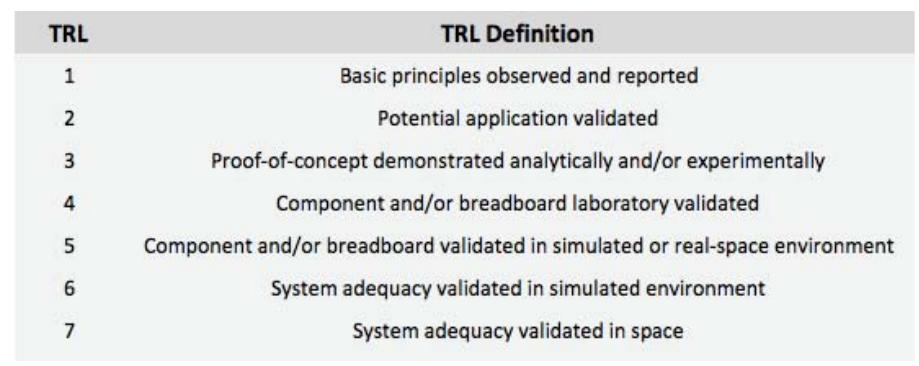

Fig. 2. First version of the TRL scale, adapted from [1]

After being confined within NASA for an initial period, the method was 'discovered' by other federal agencies, and 
ultimately it started to be adopted by companies. The NASA scale was not, however, perfectly replicable for all other companies and institutions that were willing to have a technology readiness measurement. NASA introduced the scale and all the concepts around it were developed with the aircraft/aerospace industry in mind. Moreover, it had also been primarily thought to measure hardware technology readiness (any technology involving manufacturing processes). Soon, the basic question for other organizations was: how to adapt the scale to our specific needs?

The Department of Defense (DoD) and the Department of Energy (DoE) have made some modifications to the levels definitions in order to reflect their own applications/requirements [23], [24] - see figures below (Fig.3 and Fig. 4). As explained in [25], “...the basic idea associated with these other applications and uses remains the same as in Mankins' TRL scale".

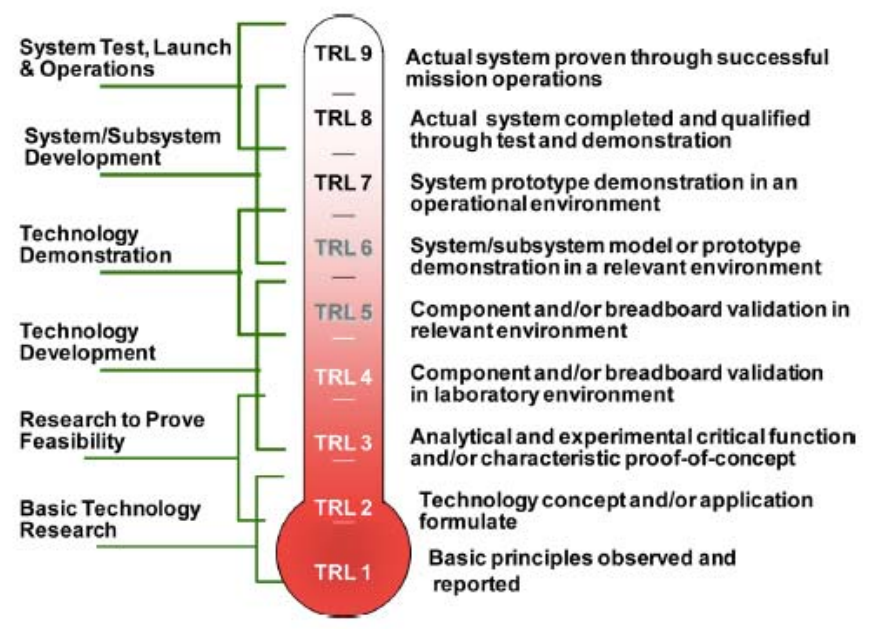

Fig. 3. TRL Definitions for DoD [23]

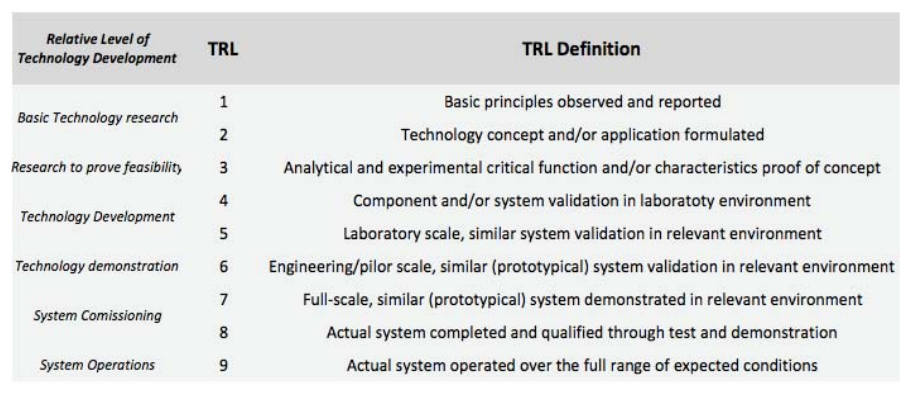

Fig. 4. TRL Definitions for DoE [24]

Private companies are acknowledging the usefulness of TRLs as they start to implement the method, but unlike many managerial innovations, TRL`s were born, tested and evolved in the public sector, e.g. NASA and DoD. Due to the nature of these agencies (non-profit and oriented towards breakthrough technological innovations), in most cases the technological development occurs within the 'product development' process, i.e. the system/product is envisioned counting on technologies yet to be developed/matured, and investments are made even though these technologies have not yet proven to be ready.
Conversely, in the private sector, organizations usually wait until a technology is mature in order to consider it for a product/system, so that they lower the risks of a new product development project. Thus, for private firms, the notcompletely mature technologies would be blocked at the beginning of the innovation funnel, giving way to proven and functioning ones. Nevertheless, the accelerated pace in which high technology firms compete nowadays might have forced them to start considering less mature technologies for new products/processes. Furthermore, using TRL's can potentially bring other benefits rather than just providing a snapshot of the development stage of a technology.

The method, however useful and innovative, also presents some shortcomings and limitations. As its popularity grows, the willingness for scholars to study it grows as well, and some of its downsides start to surface. Some of these downsides are listed and defined in [26], [27]. The lack of objectivity is one of the most notorious downsides. Once all the analysis relies on subjective observations and no quantitative aspects are involved, subjectivity is pointed as a weakness, as in [28]. Researchers also note that TRLs are effective for measuring a single technology readiness, but most of the technologies work integrated with other technologies. This integration assessment is also considered one of the major weaknesses, as mentioned in [29]. As aforementioned, TRLs provide a frozen image representation of the technological development stage. This, for some researchers, such as [4], is a shortcoming because the method fails to measure and communicate how difficult a further development will be, e.g. how difficult it is to bring technology A from TRL ' $x$ ' to TRL ' $y$ '. Another commonly pointed weakness is the generality of the scale definitions. As the scale was conceived to serve as many different technologies as possible, there is a lack of accurate definitions on the scale, which can pose some challenges for practitioners, as stated in [30]. Other downsides identified in the literature are the lack of a standard implementation process [31], the lack of a comparative analysis of different technologies TRLs [32], the problem of 'updating' the TRL once the technology is obsolete [33], how to deal with the TRL when a new component is added to the technology or when a new application is tested [34], the lack of a system-based assessment (derives from the integration weakness) [35], the problem of applying TRLs for non-hardware technologies [36], and the lack of the assessment of the technology's criticality to its system or program [8].

Although challenges and downsides seem to be plentiful, researchers also started to address some of these weak points. Some new methods and complementary tools are being studied and developed in order to tackle and mitigate TRLs weaknesses. In [32], Sauser presents the basic concept of its System Readiness Level (SRL) - a new metric, derived from TRL, which aims to deal with the system and integration downsides. A few years later, Sauser improves SRL and presents its final version along with another nine-point scale called Integration Readiness Level (IRL) [29]. In 1998, John Mankins developed a new metric called Research and Development Degree of Difficulty (R\&D3) [37], which attempts to alleviate one of the most recurrently mentioned flaws of TRL - the inability to assess/forecast the hardships 
one will encounter should one chooses to continue the development of a technology. Other metrics created by Sauser is the Integrated Technology Index (ITI) and Integration Maturity Metric (IMM) [38]. Some of these metrics are further explained in [39], [40] and combined in [41]. Although advancements have been made since the introduction of these tools, there are still several problematic points to be tackled when it comes to dealing with TRL's weaknesses, as evidenced in [42]-[45].

\section{RESULTS AND DisCUSSION}

When asked to classify the level of importance of TRLs for $\mathrm{R} \& \mathrm{D}$ activities, the respondents, in its majority, classified it as "very important" - in a 5-level scale from not important at all through extremely important, as shown in fig. 5.

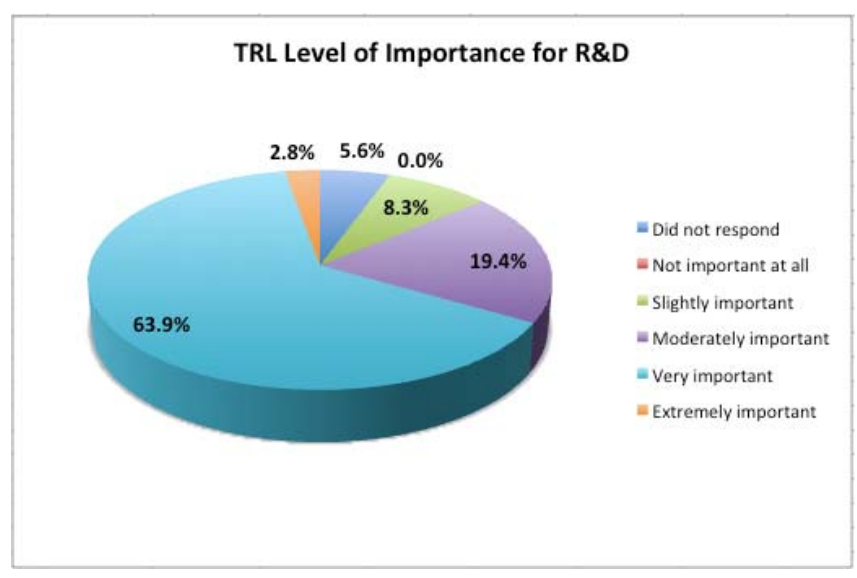

Fig. 5. TRL Level of importance for R\&D

The participants were asked to state the main reason why they study and/or apply TRLs. The vast majority of respondents stated that they have the need to determine how ready a certain technology is and TRLs are the benchmark or the standard to do this job. A Program Analyst states that "It is a standard used within technology research field", and a Research Engineer says "It is relevant to Systems Engineering and Systems Development". Other reasons respondents mentioned were: TRLs being required by customers; Technology Transfer and Protection; as a control method for the innovation portfolio; to study University spin-offs.

In the interview, we asked the participants if they were aware of any metrics or methods that would substitute TRLs. There are four main themes identified, namely CMMI, TRL derivatives, PMBOK and other metrics.

The Capability Maturity Model Integration (CMMI) is a process improvement framework and program, developed by the Carnegie Mellon University. It is focused on process enhancement and it has three main branches: development, services and acquisition. According to [46], it describes an "evolutionary improvement path from ad hoc, immature processes to disciplined, mature process with improved quality and effectiveness". The TRL derivatives are mainly the Integration Readiness Levels (IRL), System Readiness Levels (SRL), Research and Development Degree of Difficulty (RD3) and Manufacturing Readiness Levels (MRL). These are metrics that have TRL as a basis and try to tackle some of its challenges and disadvantages, as described in [47] [48] [49]. The PMBOK (Project Management Body of Knowledge) is a comprehensive toolset organized by the Project Management Institute (PMI), and it contains a whole myriad of project management-related tools and methods [50]. Other metrics mentioned were Score Cards [51], Project Management Maturity Model (PMMM) [52], Organizational Project Management Maturity Model (OPM3) [53, p. 3], Stage-Gates [54], Critical Technology Elements (CTE) [55] and more empirical methods such as iterative cycles of deployment and testing on the field and relying on customer feedback along the technology development process.

Being TRLs a metric that deals specifically with technology development, none of the mentioned methods (with the exception of the TRL derivatives) could fully substitute TRLs. One of the respondents said that, even though he believes the CMMI to be able to properly measure the maturity of a project, "It presents a focus on service and product development, rather than technology development'. These other metrics could, however, complement it. Another respondent said that TRL should be applied in conjunction with other metrics, because "they all relate to uncertainty, feasibility and synchronization of innovation efforts across functions and levels".

Understanding that the majority of the respondents believes that TRLs could be swapped by any of these other metrics without any major difference, we can argue that, in general, practitioners and researchers are perhaps misunderstanding the real meaning and purpose of applying Technology Readiness Levels, leading us to the hypothesis: Practitioners and researchers, in general, do not fully understand the meaning and purpose of TRLs yet.

Respondents were also inquired about the issues they perceive on TRLs when applying and/or studying the tool. There are five themes identified in the gathered data: subjectivity; definitional challenges; lack of integration and systems perspectives; TRLs not being well understood; other issues.

The first main theme is the subjectivity. Researchers and practitioners argue that the tool is less scientific and more "gut feeling" than it should be. A researcher states "there is not much intellectual or empirical basis for it". Some TRL calculators have been developed trying to tackle this issue. The definitions of each level are also troublesome, as sometimes it is difficult to adapt the general definitions of the scale to the actual situation/sector one is trying to apply the scale to. The lack of integration and systems perspectives are heavily noted. A Professor notes that "A fundamental issue with TRL is the lack of attention to integration and the influence integration has on the overall readiness of a system". Tools such as IRL and SRL were created exactly to overcome these barriers. A problematic point mentioned by several respondents was the fact that TRLs must be well known and understood within an organization in order for it to produce good results. A participant notes that "When every stakeholder understands TRL, it enables a meaningful and directed discussion". Other 
issues mentioned in the data are the difficulty in assigning the responsible for determining the level; the scale being over simplistic and overseeing important details of a technology; TRL not being able to address all complexities of project management.

The issues and challenges related to TRLs and identified in this study are consonant with the literature. It has being well documented by researchers in the last few years. Among important works, we could refer the reader to the research by Olechowski et. al, 2015 [28] and Mankins, 2009 [4].

The participants were asked to think about and explain the benefits TRLs bring. The results were a wide range of perceived benefits, among which five were more recurrent and strongly perceived, as follows:

- It is an accurate technology assessment metric, enabling better decision-making

- It is a simple framework and an effective management tool

- It enhances the organization's communication abilities

- It helps balance the technology/projects portfolio

- It reduces risk in technology development

The first benefit comes out of the understanding TRL provides about the technology's characteristics - what it can do and when. Although TRL does not provide a precise level of effort required to move on from level to level (that could be provided by a complementary metric, such as RD3), it tells the stakeholders where the technology is in the development path at that moment in time, providing them with a good basis for making decisions. A technology development manager states that, by using TRLs, the company "has become more accurate in predicting what a technology can do before moving it to a NPI (New Product Introduction) program". Another respondent says "TRLs enable a better technology assessment, thus you have more chances to make the right decision".

Notwithstanding being called over simplistic by many, TRL is also praised for the same reason. Several participants have expressed that TRL is an effective management tool precisely because it is simple and straightforward. A project manager argues that TRLs are beneficial because "the scale is a shorthand framework trying to communicate complex dynamics in a simplified manner". Furthermore, a researcher says "it is a simple framework that people can easily understand, which makes it effective". As discussed earlier in this section, there is the notion that TRLs must be well understood in order to produce good results. Conversely, there is the notion that TRLs are very simple and easily understandable. That seem to be a contradictory point. Since the tool is very simple, no organization should have any issues in trying to communicate the purpose and usage of TRLs. This gives us the ability to formulate another hypothesis: the scale and its concept are simple, but to properly implement it and use it as a decision-aid is not.
TABLE I. TRL BENEFITS

\begin{tabular}{|c|c|c|}
\hline \multicolumn{3}{|c|}{ Benefits brought by Technology Readiness Levels (TRL) } \\
\hline Benefit & Definition & $\begin{array}{c}\text { \% of } \\
\text { respondents }\end{array}$ \\
\hline $\begin{array}{l}\text { It is an accurate technology assessment metric, enabling } \\
\text { better decision-making }\end{array}$ & Better understanding of the technology provides better basis for decisions & $19 \%$ \\
\hline It is a simple framework and an effective management tool & Its simplicity makes it effective & $19 \%$ \\
\hline It enhances the organization's communication abilities & By creating a common language regarding technology development & $14 \%$ \\
\hline It helps balance the technology/projects porttolio & Provides information to group technologies according to its characteristics & $11 \%$ \\
\hline It reduces risk in technology development & Provides information to understand and manage the risks & $11 \%$ \\
\hline It reduces waste in R\&D efforts & Provides information to make technology development more efficient & $11 \%$ \\
\hline It is a guidace from basic R\&D through operations & $\begin{array}{l}\text { Provides a snapshot in time of the technology's position in the developmetn } \\
\text { path }\end{array}$ & $8 \%$ \\
\hline It increases awareness of the technology development & Creates a better understanding of the technology development process & $8 \%$ \\
\hline It helps apply scarce resources to the right projects & $\begin{array}{l}\text { By understanding the position of a technology in the development path and } \\
\text { contrasting it against the organization's needs, a manager can better assign } \\
\text { resources }\end{array}$ & $8 \%$ \\
\hline It allows different technologies to be compared & It is a comparative tool that works across different technology types & $6 \%$ \\
\hline It enhances customer confidence & $\begin{array}{l}\text { Customers are more confident when they know TRL is being used by the } \\
\text { technology developer }\end{array}$ & $6 \%$ \\
\hline It increases recognition and atracts funding & $\begin{array}{l}\text { It is a benchmark that could lead to a better status as a technology developer } \\
\text { and make it teasier to access funding }\end{array}$ & $6 \%$ \\
\hline It helps to identify a technologys applicablilty & $\begin{array}{c}\text { It allows a better reffexion of a technology's suitability for a certain } \\
\text { application }\end{array}$ & $6 \%$ \\
\hline It increases the R\&D rate of success & A side-effect of making better decisions & $6 \%$ \\
\hline It enables a more successful systems development process & A side-effect of making better decisions & $6 \%$ \\
\hline $\begin{array}{l}\text { It creates a reference in planning and controlling technology } \\
\text { develoment }\end{array}$ & It gives credibility to the technology development process. & $6 \%$ \\
\hline It brings systematic improvement to NPD and R\&D & $\begin{array}{l}\text { By making better informed decisions overtime, the NPO and R\&O funcions are } \\
\text { Improved }\end{array}$ & $6 \%$ \\
\hline It brings strategic alignment & $\begin{array}{l}\text { By understanding the nature and development path of a technology, it is } \\
\text { easier to strategically align it }\end{array}$ & $6 \%$ \\
\hline It helps technology transfer & Provides information on when to transfer a technology & $3 \%$ \\
\hline It helps to assign responsibilities & $\begin{array}{l}\text { By understanding the current status of a technology, it would be easier to } \\
\text { assign the responsibles for tackling specific challenges }\end{array}$ & $3 \%$ \\
\hline It helps to understand startups & $\begin{array}{l}\text { Creates a better understanding of University spin-offs based on their } \\
\text { technology maturity level }\end{array}$ & $3 \%$ \\
\hline It increases R\&D reliability and robustness & By providing a stronger control and planning tool & $3 \%$ \\
\hline It reduces time to launch & $\begin{array}{l}\text { By providing information on potential problems and delays, managers can } \\
\text { plan and tackle problems, uttimately reducing time to launch }\end{array}$ & $3 \%$ \\
\hline It increases cost savings & $\begin{array}{l}\text { By providing information on potential problems and delays, managers can } \\
\text { plan and tackle problems, ultimately reducing costs }\end{array}$ & $3 \%$ \\
\hline It supports knowledge management & $\begin{array}{l}\text { By creating reports on the TRL assessments, knowiedge can be transmitted } \\
\text { more easiy }\end{array}$ & $3 \%$ \\
\hline
\end{tabular}

Another very important benefit TRL brings, according to the participants, is the to enhance the organization's communication abilities. By using TRLs, it would be easier to communicate and discuss within the technology development team and among different audiences and stakeholders, which in turn makes it easier and faster to make decisions - and better decisions. It is almost unanimous that TRLs bring a "shared understanding of the technology development, while enhancing cross-functional communication", as a researcher puts it. Another researcher argues that "TRLs create a common language to communicate maturity and mutual understanding in a project team".

Another finding relates the usage of TRLs with the betterment of the technology/project portfolio. By being more aware of the readiness level of its technologies, a manager is more comfortable to balance the portfolio, according to the organization's strategy. Participants say that TRLs can help in creating and managing a portfolio and pipeline of technologies and projects.

Last among the most important TRL benefits found by this study is the decreased risk in technology development. Again, based on the premise that TRLs provide managers with a better and clearer picture of each technology, it would be easier for them to spot the weakest points and tell how risky each project/technology is, ultimately providing information to reduce those risks. Transcribing the words of a respondent, "TRL is a useful method to increase the robustness of a project and to manage its risks". Another respondent adds that "the R\&D team can use it to better evaluate the project risks". 
As aforementioned, a whole myriad of perceived benefits were reported, to a lesser or greater extent. All the benefits mentioned by the participants are shown in table 1, along with the percentage of respondents that mentioned it.

When prompted to point out the most important R\&D issues organizations face nowadays, respondents mentioned a wide variety of topics, summarized in table 2 .

TABLE II. MOST IMPORTANT R\&D ISSUES

\begin{tabular}{|c|c|c|}
\hline \multicolumn{3}{|c|}{ Most Important R\&D Issues } \\
\hline Issue & Definition & $\begin{array}{c}\% \text { of } \\
\text { respondents }\end{array}$ \\
\hline Availability of Funds & Lack of funding or porrly managed funds & $14 \%$ \\
\hline Risk and Uncertainty management & Poorly managed financial and technical risks & $14 \%$ \\
\hline Create results that can cross the chasm & Level of successful R\&D projects below the expected & $11 \%$ \\
\hline Complexity & Complex markets and technologies make it hard to manage $R \& D$ projects & $8 \%$ \\
\hline Lack of good metrics & There are numerous toois but they present substantial deployment challenges & $8 \%$ \\
\hline People Management & It is difficult to train, motivate and assign responsibilities to the right people & $8 \%$ \\
\hline Technology Readiness & It is difficult to tell when the technology is ready to be deployed & $8 \%$ \\
\hline Knowledge management & It is difficult to learn from the past and systematically improve processes & $5 \%$ \\
\hline Lack of a standard process & $\begin{array}{l}\text { Lack of procedures to make R\&D be more repeatable and thus more } \\
\text { controllable }\end{array}$ & $5 \%$ \\
\hline Lack of time for development & It is difficult to keep projects on time and avoid delays & $5 \%$ \\
\hline $\begin{array}{l}\text { Lack of measurements of translational } \\
\text { research }\end{array}$ & It is hard to control and measure interdisciplinary research works & $3 \%$ \\
\hline Interorganizational collaborations & It is difficult to communicate, measure and control joint research efforts & $3 \%$ \\
\hline Portfolio management & $\begin{array}{l}\text { It is difficult to create and maintain a baanced portfolio of technologies and } \\
\text { projects }\end{array}$ & $3 \%$ \\
\hline Cost reduction & Inneficiencies and lack of control in R\&D activities & $3 \%$ \\
\hline Strategic alignment & $\begin{array}{l}\text { It is difficult to create and maintain a portfolio of technologies and projects } \\
\text { that reflect the organization's strategy }\end{array}$ & $3 \%$ \\
\hline
\end{tabular}

Going over the data, there are no explicit relationships between R\&D issues and TRL benefits identified in this research. However, the majority of the respondents agree that TRL is important to the R\&D function, and analyzing the benefits the respondents listed, it is possible to connect the dots and formulate some hypotheses. To a lesser or greater degree, TRLs can help tackle the R\&D issues identified in this study:

- Availability of Funds: TRLs would help organizations to better manage their R\&D funding (by providing more accurate information) as well as to attract more funding opportunities.

- Risk and uncertainty management: TRLs would help organizations manage and decrease the risk levels in $\mathrm{R} \& \mathrm{D}$ (by helping to identify weak and risky points in the projects)

- Create results that can cross the chasm: TRLs would increase the rate of successful $R \& D$ projects

- Complexity: TRLs would communicate complex dynamics in a simple manner, allowing managers to make decisions more rapidly and in a more agile fashion.

- Lack of good metrics: TRLs are seen as a standard, simple and efficient metric

- People management: TRLs would make it easier to communicate with different stakeholders and also would make it easier to assign responsibilities to people.

- Technology Readiness: TRLs would first and foremost tell how ready a technology is.

- Knowledge management: TRLs would help knowledge to be transmitted more easily, by ways of enhancing communication capabilities and by formalizing the technology assessment process.

- Lack of a standard process: TRLs can be regarded as a formal procedure for assessing a technology and would improve the control and repeatability of the technology development process.

- Lack of time for development: Although TRLs will not buy any time for organizations, it can avoid delays by providing accurate information regarding the current status of a technology.

- Lack of measurements of translational research: To some extent, TRLs would help people with different backgrounds to communicate and work together, which is essential in interdisciplinary research activities.

- Inter-organizational collaborations: To some extent, TRLs would help people with different backgrounds to communicate and work together, which is essential in joint research activities.

- Portfolio management: TRLs would help organizations to balance their portfolios by providing accurate information about technologies

- Cost reduction: Although TRLs will not directly reduce costs for organizations, it can avoid inefficiencies and unnecessary efforts by providing accurate information regarding the current status of a technology

- Strategic alignment: TRLs would make it easier for managers to align their R\&D to the overall strategy, by understanding the nature and the development path of a technology.

Fig. 6 shows a graphical representation of how TRL benefits are related and could tackle R\&D issues. The issues (represented by the orange boxes) are addressed by at least one benefit (represented by the blue boxes) and TRL's simplicity and effectiveness is the central actor that generates and unites all other benefits.

\section{CONCLUSIONS}

This study aimed to shed a light on Technology Readiness Levels, to define and present the metric and also to understand the potential benefits it can bring to technology development and research and development. Interviews were conducted with researchers and practitioners and Grounded Theory was used as a qualitative data analysis methodology, with the aid of the software Atlas.ti.

The findings can be divided into sub-groups: importance of TRL for the R\&D function; reason why TRL is used; similar and substitute metrics; TRL issues; TRL benefits; R\&D issues.

The majority of respondents believe TRLs are very important for the R\&D function (63.9\%). They acknowledge that determining the readiness of a technology is essential, and the fact that the technology readiness levels scale is seen as a standard and benchmark was pointed out as the main reason why organizations use it. Concerning similar metrics, some respondents listed TRL derivatives such as IRL and SRL. However, the majority of participants mentioned project management-related metrics, e.g. PMBOK, OPM3 and CMMI, which suitability as a TRL substitute is arguable - although those could work as complementing tools, as duly noted by 
some interviewees. To determine TRL issues and challenges was not the main objective of this study, but respondents were prompted to list what they understood to be downsides related to the tool. The subjectivity, definitional challenges, lack of integration and systems perspectives and the tool not being well understood were listed as the main issues associated with TRLs.

The main objective of this paper was to identify the benefits people perceive by using TRLs and the potential relationship those benefits could have with $R \& D$ issues organizations face, as well as the way TRLs could help tackle those issues. Respondents mentioned numerous and diverse benefits brought about by the usage of TRLs, chief among which are: TRL is an accurate technology assessment metric, enabling better decision-making; it is a simple framework and an effective management tool; it enhances the organization's communication abilities; it helps balance the technology/projects portfolio; it reduces risk in technology development. As for the R\&D issues, respondents identified lack of funds, risk and uncertainty management and unsuccessful R\&D projects as the most important ones, followed by a variety of less important ones.

By analyzing both TRL benefits and R\&D issues in the data, we were able to create connections between those and propose hypotheses on how TRLs are/could be tackling the R\&D issues. Moreover, the most mentioned TRL benefit is that the tool is a very simple and effective management tool (along with the "accurate technology assessment metric"), and we believe that this simplicity and effectiveness is the central factor from which all other benefits are generated and perceived.

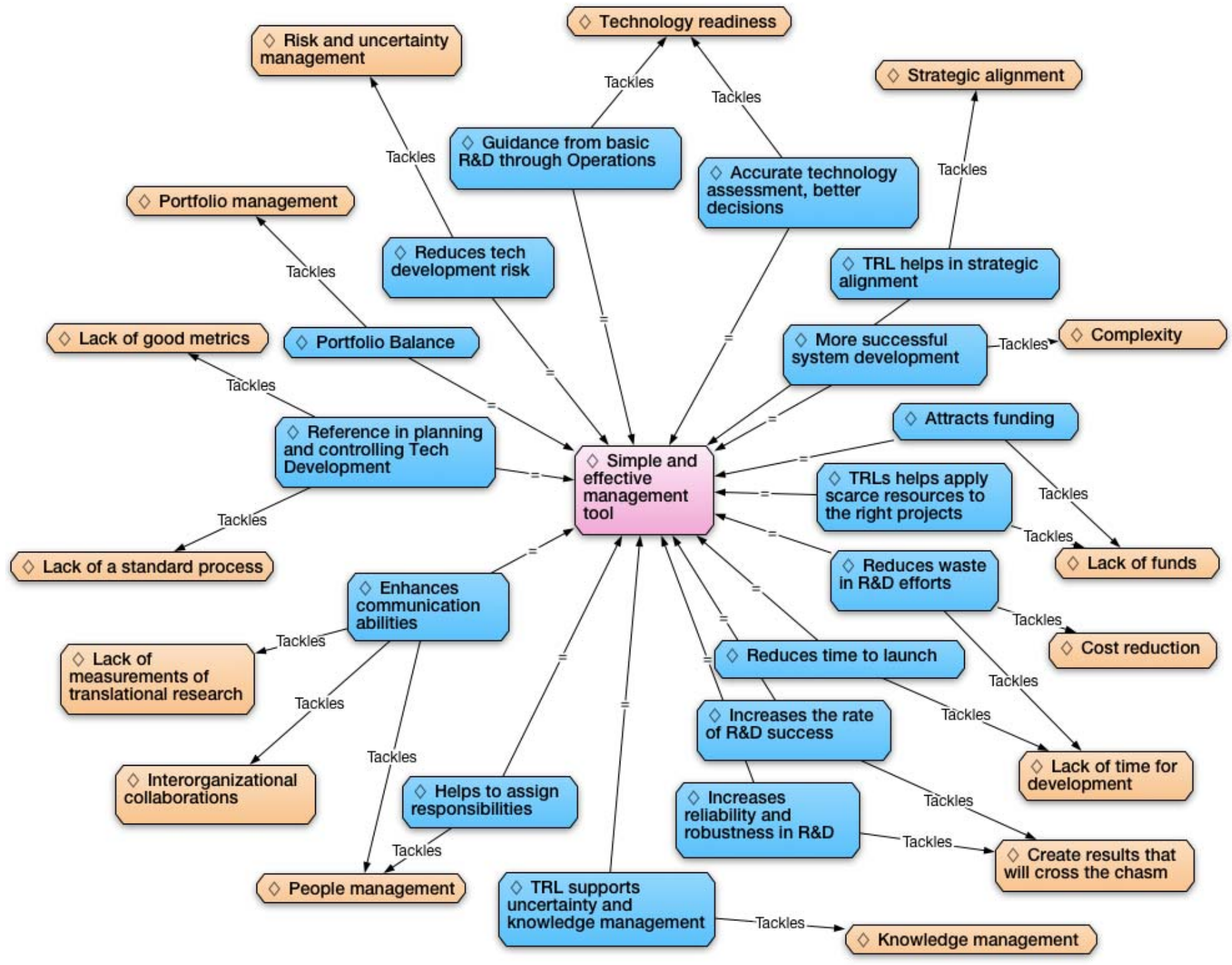

Fig. 6. TRL benefits vs R\&D issues network 


\section{FUTURE RESEARCH}

This research represents an attempt to understand if, how and to what extent Technology Readiness Levels can be beneficial to organizations - especially with regards to better their research and development function.

Having used Grounded Theory as a methodology, some hypotheses were generated, all of which could be further investigated by other research works, in order to confirm or refute them.

Following are the hypotheses proposed in this study:

- Practitioners and researchers, in general, do not fully understand the meaning and purpose of TRLs yet.

- They usually take TRLs as another project management tool that could be easily substituted.

- The scale and its concept are simple, but to properly implement it and use it as a decision-aid is not.

- People recognize TRL's simplicity as a benefit, but at the same time they say that, if the tool is not properly known and understood by all stakeholders, benefits will not be realized.

- TRL brings actual benefits to organizations

- Regarding the benefits shown in table 1 , data should be collected in order to prove to what extent each benefit is linked to the tool's implementation and usage.

- TRL's simplicity is the main theme around which all other benefits revolve

- Further research should be conducted in order to determine to what extent TRL's simplicity is an advantage and what would be the consequences of making it more complex to tackle inherent systems complexities.

\section{REFERENCES}

[1] [1] S. R. Sadin, F. P. Povinelli, and R. Rosen, "The NASA Technology Push Towards Future Space Mission Systems," Acta Astronaut., vol. 20, pp. 73-77, 1989.

[2] [2] J. C. Mankins, "Technology Readiness Levels," White Pap. April, vol. 6 , no. 2 , p. $5,1995$.

[3] [3] N. Azizian, T. Mazzuchi, S. Sarkani, and D. F. Rico, "A Framework for Evaluating Technology Readiness, System Quality, and Program Performance of U.S. DoD Acquisitions," Syst. Eng., vol. 14, no. 4, pp. 305-326, Dec. 2011.

[4] [4] J. C. Mankins, "Technology readiness assessments: A retrospective," Acta Astronaut., vol. 65, no. 9-10, pp. 1216-1223, Nov. 2009.

[5] [5] K. Charmaz, "Constructing grounded theory: A practical guide through qualitative research," SagePublications Ltd Lond., 2006.

[6] [6] B. G. Glaser and A. L. Strauss, "The discovery of grounded theory: Strategies for qualitative research. Piscataway," NJ Trans., 1967.

[7] [7] R. Thornberg and K. Charmaz, "Grounded theory and theoretical coding," SAGE Handb. Qual. Data Anal., pp. 153-169, 2014.
[8] [8] J. D. Smith, "An Alternative to Technology Readiness Levels for Non-Developmental Item (NDI) Software," Proc. 38th Annu. Hawaii Int. Conf. Syst. Sci., vol. 0, no. C, p. 315a-315a, 2005.

[9] [9] A. Ardilio, J. Warschat, and D. Spath, "Customized Technology Readiness: Introducing the Application Specific Technology Readiness Model," PICMET 12 Proc. - Technol. Manag. Emerg. Technol., pp. 1260-1272, 2012.

[10] [10] D. Clausing and M. Holmes, "Technology Readiness," Res. Technol. Manag., vol. 53, no. 4, pp. 52-59, 2010.

[11] [11] T. Altunok and T. Cakmak, "A technology readiness levels (TRLs) calculator software for systems engineering and technology management tool," Adv. Eng. Softw., vol. 41, no. 5, pp. 769-778, 2010.

[12] [12] H. Jimenez, J. Schutte, and D. Mavris, "System readiness and risk assessment for advanced vehicle concepts - discussion of fundamental concepts," 49th AIAA Aerosp. Sci. Meet. New Horiz. Forum Aerosp. Expo., 2011.

[13] [13] H. Jimenez and D. N. Mavris, "Characterization of Technology Integration Based on Technology Readiness Levels," J. Aircr., vol. 51, no. 1, pp. 291-302, Jan. 2014.

[14] [14] R. M. Mackey, "Assessing and Maturing Technology Readiness Levels," in System Health Management: With Aerospace Applications, no. January, 2011, pp. 145-157.

[15] [15] D. J. Moorhouse, "Detailed Definitions and Guidance for Application of Technology Readiness Levels," J. Aircr., vol. 39, no. 1, pp. 190-192, 2002.

[16] [16] D. Corin-Stig, U. Högman, and D. Bergsjö, "Assessment of Readiness for Internal Technology Transfer - A Case Study," 21st Annu. Int. Symp. Int. Counc. Syst. Eng. INCOSE 2011, vol. 1, no. Malik 2002, pp. 893-907, 2011.

[17] [17] K. Gerdes, S. P. Schneider, and M. Cercy, "Risk reduction through use of external technical reviews, technology readiness assessments, and technical risk ratings," Trans. Am. Nucl. Soc., vol. 101, 2009.

[18] [18] E. Kujawski, "Analysis and critique of the system readiness level," IEEE Trans. Syst. Man Cybern. Part ASystems Hum., vol. 43, no. 4, pp. 979-987, Jul. 2013.

[19] [19] M. Sarfaraz, B. J. Sauser, and E. W. Bauer, "Using System Architecture Maturity Artifacts to Improve Technology Maturity Assessment," Procedia Comput. Sci., vol. 8, pp. 165-170, 2012.

[20] [20] M. S. Tillack et al., "AN EVALUATION OF FUSION ENERGY R\&D GAPS USING TECHNOLOGY READINESS LEVELS," FUSION Sci. Technol., vol. 56, no. 2, pp. 949-956, Aug. 2009.

[21] [21] C. Tugurlan, H. Kirkham, and D. Chassin, "Software Technology Readiness for the Smart Grid," PNSQC 2011 Proc., pp. 1-11, 2011.

[22] [22] J. Fernandez, "Contextual Role of TRLs and MRLs in Technology Management," Sandia Natl. Lab. SAND2010-7595, no. November, 2010.

[23] [23] N. Azizian, T. Mazzuchi, S. Sarkani, and D. F. Rico, "A framework for evaluating technology readiness, system quality, and program performance of U.S. DoD acquisitions," Syst. Eng., vol. 14, no. 4, 2011.

[24] [24] DoE, "Standard Review Plan (SRP) Technology Readiness Assessment Report," Available Online, no. March, 2010.

[25] [25] E. H. Conrow, "Estimating Technology Readiness Level Coefficients," J. Spacecr. Rockets, vol. 48, no. 1, pp. 146-152, Jan. 2011.

[26] [26] S. L. Cornford and L. Sarsfield, "Quantitative methods for maturing and infusing advanced spacecraft technology," 2004 IEEE Aerosp. Conf. Proc., pp. 663-681, 2004.

[27] [27] R. B. Magnaye, B. J. Sauser, and J. E. Ramirez-Marquez, "System development planning using readiness levels in a cost of development minimization model," Syst. Eng., vol. 13, no. 4, 2010.

[28] [28] A. Olechowski, S. D. Eppinger, and N. Joglekar, "Technology Readiness Levels at 40: A Study of State-of-the-Art Use, Challenges, and Opportunities," in PICMET 2015, 2015, pp. 2084-2094.

[29] [29] B. J. Sauser, J. E. R. Marquez, D. Henry, and D. DiMarzio, "A system maturity index for the systems engineering life cycle," Int. J. Ind. Syst. Eng., vol. 3, no. 6, p. 673, 2008.

[30] [30] N. Islam and E. Brousseau, "Implementing a multi-staged methodology to micro and nanotechnology: Technology maturity assessment and framework," Int. J. Product. Amp Perform. Manag., vol. 63 , no. 2, 2014

[31] [31] N. Azizian, S. Sarkani, and T. Mazzuchi, "A Comprehensive Review and Analysis of Maturity Assessment Approaches for Improved 
Decision Support to Achieve Efficient Defense Acquisition ," Proc. World Congr. Eng. Comput. Sci., vol. 2, 2009.

[32] [32] B. Sauser, D. Verma, J. Ramirez-Marquez, and R. Gove, "From TRL to SRL: The concept of systems readiness levels," Conf. Syst. Eng. Res. Los Angel. CA, pp. 1-10, 2006.

[33] [33] R. Valerdi and R. J. Kohl, "An Approach to Technology Risk Management," Eng. Syst. Div. Symp., pp. 1-8, 2004.

[34] [34] J. D. Smith II, "ImpACT: An alternative to technology readiness levels for commercial-off-the-shelf (COTS) software," Lecture Notes in Computer Science (including subseries Lecture Notes in Artificial Intelligence and Lecture Notes in Bioinformatics), vol. 2959. SpringerVerlag, Berlin, Germany, pp. 127-136, 2004.

[35] [35] J. Straub, "In search of technology readiness level (TRL) 10," Aerosp. Sci. Technol., vol. 46, pp. 312-320, Oct. 2015.

[36] [36] S. J. Leete, R. A. Romero, J. A. Dempsey, J. P. Carey, H. P. Cline, and C. F. Lively, "Technology Readiness Level Assessment Process as Applied to NASA Earth Science Missions," AIAA SPACE 2015 Conf. Expo., 2015.

[37] [37] J. C. Mankins, "Research \& development degree of difficulty (R\&D3)," White Pap. March, pp. 1-3, 1998.

[38] [38] B. R. E.-M. J. E. Sauser, R. Gove, E. Forbes, and J. E. RamirezMarquez, "Integration maturity metrics: Development of an integration readiness level. ," InformationKnowledgeSystems Manag., vol. 9, no. 1, 2010.

[39] [39] J. C. Mankins, "Approaches to strategic research and technology (R\&T) analysis and road mapping," Acta Astronaut., vol. 51, no. 1-9, pp. 3-21, 2002.

[40] [40] S. Yasseri, "Subsea system readiness level assessment," Underw. Technol., vol. 31, no. 2, pp. 77-92, Mar. 2013.

[41] [41] J. C. Mankins, "Technology readiness and risk assessments: A new approach," Acta Astronaut., vol. 65, no. 9-10, pp. 1208-1215, Nov. 2009.

[42] [42] L. Chang, M. Li, B. Cheng, and P. Zeng, "Integration-centric approach to system readiness assessment based on evidential reasoning," J. Syst. Eng. Electron., vol. 23, no. 6, pp. 881-890, Dec. 2012.

[43] [43] M. F. Austin and D. M. York, "System Readiness Assessment (SRA) an illustrative example," Procedia Comput. Sci., vol. 44, pp. 486-496, 2015.
[44] [44] B. Atwater and J. Uzdzinski, "Wholistic Sustainment Maturity: The Extension of System Readiness Methodology across all Phases of the Lifecycle of a Complex System," Procedia Comput. Sci., vol. 28, pp. 601-609, 2014.

[45] [45] B. Hicks, A. Larsson, S. Culley, and T. Larsson, "A METHODOLOGY FOR EVALUATING TECHNOLOGY READINESS DURING PRODUCT DEVELOPMENT," ICED 09 17TH Int. Conf. Eng. Des. VOL 3 Des. Organ. Manag., vol. 3, pp. 157$168,2009$.

[46] [46] S. C. P. Team, CMMI for Development v1. 3. Lulu. com, 2010.

[47] [47] B. Sauser, D. Verma, J. Ramirez-Marquez, and R. Gove, "From TRL to SRL: The concept of systems readiness levels," Conf. Syst. Eng. Res. Los Angel. CA, pp. 1-10, 2006.

[48] [48] J. C. Mankins, "Research \& development degree of difficulty (R\&D3)," White Pap. March, pp. 1-3, 1998.

[49] [49] J. Fernandez, "Contextual Role of TRLs and MRLs in Technology Management," Sandia Natl. Lab. SAND2010-7595, no. November, 2010.

[50] [50] "PMBOK\&reg; Guide and Standards." [Online]. Available: https://www.pmi.org/pmbok-guide-standards. [Accessed: 21-Dec-2016].

[51] [51] M. Martinsons, R. Davison, and D. Tse, "The balanced scorecard: a foundation for the strategic management of information systems," Decis. Support Syst., vol. 25, no. 1, pp. 71-88, 1999.

[52] [52] J. K. Crawford, Project management maturity model. Taylor \& Francis, 2007.

[53] [53] P. Ghoddousi, Z. Amini, and M. R. Hosseini, "A survey on the maturity state of Iranian grade one construction companies utillzing OPM3 maturity model," Tech. Technol. Educ. Manag., vol. 6, no. 1, pp. 69-77, 2011.

[54] [54] R. G. Cooper, "Perspective: The stage-gate ${ }^{\circledR}$ idea-to-launch process - update, what's new, and nexgen systems," J. Prod. Innov. Manag., vol. 25, no. 3, pp. 213-232, 2008.

[55] [55] J. Mandelbaum, "Identifying and Assessing Life-Cycle-Related Critical Technology Elements (CTEs) for Technology Readiness Assessments (TRAs)," DTIC Document, 2006. 